\title{
Analysis of the impact of the eastern ring road of Lodz on selected components of the environment
}

\author{
Monika Janas, ${ }^{*}$, Alicja Zawadzka \\ Lodz University of Technology, Faculty of Process and Environmental Engineering, 90-924 Lodz, \\ Wolczanska 213, Poland
}

\begin{abstract}
The geographical location of Poland and the pursuit of economic growth make it necessary to build a sufficiently equipped and compact network of expressways and motorways. Such investments do not, however, leave the environment unaffected. The work analyzes changes that have occurred in the natural environment under the influence of the construction and operation of Lodz eastern ring road being a section of the A1 motorway commissioned in August 2016. Changes in the pollution of air, soil and acoustic climate are discussed in detail.
\end{abstract}

\section{Road transport in Poland}

In Poland, numerous actions have been taken over the last few years to develop the road network and to improve its technical condition. Traffic flow and road capacity are crucial for the development of modern civilization. At the end of 2015, the network of public roads in Poland covered 419.6 thousand km, of which roads with hard surface had a length of 290.9 thousand $\mathrm{km}$ that accounted for about $70 \%$ of the length of public roads. Despite the systematic increase in the length of motorways, Poland is still among the countries with the least developed network of expressways and motorways in Europe. By the end of 2015, the total length of motorways was $1559.2 \mathrm{~km}$ and expressways $1292.2 \mathrm{~km}$ [1].

Road investments are seen as a key instrument of socio-economic development. Construction of new roads, especially motorways and expressways, plays a very important role in stimulating local business [2-4]. Today, motorways serve not only transport functions but they become a driving force for boosting business growth, revitalizing selected economic areas and reducing unemployment, and at the same time they contribute to raising the level of road safety. Such investments, however, affect the natural environment and change space organization of terrain. The range of direct impact is relatively small (several hundred meters) and due to the linear nature and investment processes affects the environment on a regional and national scale [5-8].

The negative impact of motorways on the environment is very burdensome to people. Cars driven on these roads emit to the atmosphere harmful substances which directly affect human health. As a result of fuel combustion in vehicle engines, the following pollutants

\footnotetext{
*Corresponding author: monika.janas@dokt.p.Łódź.pl
} 
are released into the air: carbon monoxide, nitric oxide, hydrocarbons including PAHs and solid particles which may contain heavy metals [6-10]. Transportation routes are also contaminated with lubricants, oils and petrol, and the poor technical condition of cars in Poland aggravates this phenomenon. Rain rinses these contaminants out of the roads and thus pollutes soil as well as surface and underground waters in the vicinity of roads. Heavy use of vehicles results in noise emissions and vibrations, worsening the acoustic environment in the vicinity of motorways. The noise level depends on traffic intensity, the weight of vehicles, technical solutions and topographical conditions. The location of communication routes affects changes in the location of fauna and flora habitats, modifies microclimate of the surrounding areas and causes environmental pollution [11-16].

The construction of new transport routes will always involve interfering with the natural environment. The purpose of environmental reports prepared by specialist teams is to answer the question: what road impacts are most likely to be significant and how they can be minimized. A well-designed and well-used road enables better city functioning by improving safety conditions, reducing road traffic and, above all, contributing to the development of the region [17-19].

\section{The purpose and area of research}

The aim of the study was to analyze the impact of the eastern ring road of Lodz on selected components of the environment. Its influence on atmospheric air, soil and acoustic climate was determined. The analyzed section of the motorway is a new Polish road investment functioning in the geographical space for a relatively short time (commissioned on 1 July 2016) and thus not all effects connected with its exploitation are already possible to assess thoroughly. Nevertheless, it was considered appropriate to undertake research to determine short-term results of the investment, which will make it possible to carry out comparative analyzes in the future.

The A1 motorway, also called the Amber Motorway, is the only motorway in Poland in meridian direction. Finally, it will be almost 570 kilometers long and will connect Trojmiasto, Torun, Lodz, Czestochowa and Upper Silesia with the state border with the Czech Republic. The A1 motorway is undoubtedly one of the pillars of the communication system in the country, because it is or will soon be connected to many other important fast traffic routes. In the north, in Rusocin, it connects to the S6 expressway, giving it a connection with the cities of the Trojmiasto agglomeration and finally with Szczecin, through Slupsk and Koszalin. In Strykow, it connects to the A2 motorway, which leads from the border with Germany to Warsaw. In the south of Lodz, the A1 motorway connects to the S8 expressway leading to Wroclaw. In Gliwice it crosses the A4 motorway, connecting the Polish border with Germany with the border with Ukraine in the east. On the southern border of the country, in Bohumín, the A1 connects to the Czech highway D1 [1]. The existing infrastructure of the motorway is shown below (Figure 1).

The analyzed section of the A1 motorway in the eastern ring road of Lodz is $30 \mathrm{~km}$ long. This part is located entirely in the Lodz Province, in the Lodz-East and Zgierz Districts and in the city of Lodz. The analyzed section of the motorway is of strategic importance for the Lodz Province, especially for the city. The A1 motorway along with the A2 motorway has taken over most of the transit traffic from the national roads in the Lodz area, which has a positive effect on their capacity and limits the transit traffic in Lodz itself. Less crowding in cities located on the outskirts of Lodz improves the safety of pedestrians, cyclists and motorists, and improves the environment. 


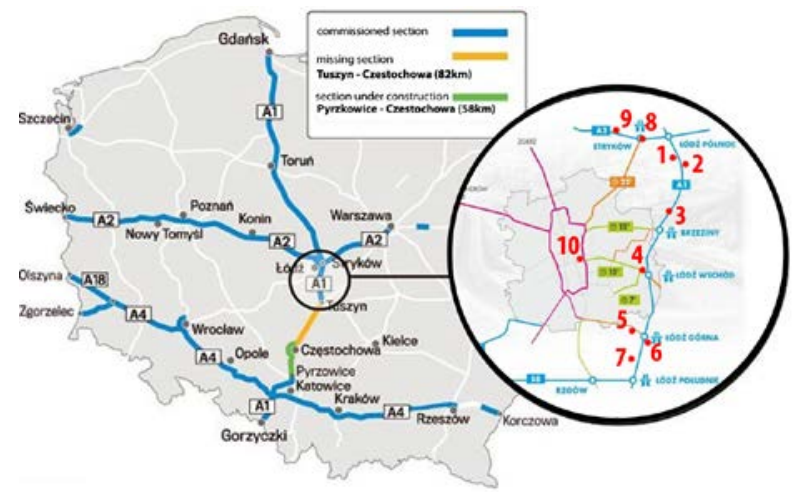

Fig. 1. A1 motorway and location of measurement points

Seven measurement points located along the eastern ring road of Lodz in the section from Skoszewy in the north (Lodz-East District) to Giemzowek in the south (Lodz-East District) were selected to analyze the environmental impact of the motorway. In two locations (Skoszewy-West and Wisniowa Gora-East) measurements were made only behind energy absorbing barriers. In addition, two measurement points were selected for comparison - one in Strykow, connecting the A2 and A1 motorways and the other one in the center of Lodz.

\section{Research methodology}

Analysis of the environmental impact of the eastern ring road of Lodz was carried out in accordance with the guidelines contained in the Ordinance of the Ministry of Environment on the requirements for measurements of substances or energy levels in the environment to be carried out by the manager of road, tram line, airport or port [20]. Periodic measurements were carried out on one of April Monday mornings with heaviest traffic under suitable meteorological conditions (wind speed below $5 \mathrm{~m} / \mathrm{s}$, air temperature above $10^{\circ} \mathrm{C}$, no precipitation, no or low ground temperature inversion).

Air samples for analysis were taken along lines running perpendicular to the road axis. The samples were taken at points located 10 to 50 meters from the road edge. The concentrations of sulfur dioxide $\left(\mathrm{SO}_{2}\right)$ and nitrogen dioxide $\left(\mathrm{NO}_{2}\right)$ were determined by gas chromatography.

Soil samples in the immediate vicinity of the motorway were collected for analysis along lines running perpendicular to the road axis. The soil was collected from the surface level (humus level A, depth $5 \mathrm{~cm}$ ) at points located 10 to 50 meters from the road edge (depending on the road infrastructure). The samples were dried at $105^{\circ} \mathrm{C}$ and then sieved through a sieve with $2 \mathrm{~mm}$ mesh size. The analyzes were performed in fraction $<2 \mathrm{~mm}$. Analysis of the content of nickel $(\mathrm{Ni})$, lead $(\mathrm{Pb})$, copper $(\mathrm{Cu})$ and zinc $(\mathrm{Zn})$ was carried out in solutions prepared on the basis of aqua regia $\left(\mathrm{HCl}: \mathrm{HNO}_{3}=3: 1 \mathrm{vol} / \mathrm{vol}\right)$. Copper $(\mathrm{Cu})$ and zinc $(\mathrm{Zn})$ content were determined by the AAS method on a Varian Spectr AA 220 spectrometer. The total content of cobalt (Co) and chromium (Cr) was determined by argon emission spectrometry [20].

Noise measurements on the analyzed section of eastern Łódź ring road were carried out with the use of an integrating SON-50 sound level meter. The meter was placed on a tripod, about $1.7 \mathrm{~m}$ above the ground. The adopted measurement level was in line with the recommendations of the International Society of Biometeorology for studies on the impact of atmospheric environment on humans. The impact of noise on the environment has been 
described by means of an average equivalent sound level, expressed in decibels. Measurement points were distributed along the profiles perpendicular to the main road. The distance of the measurement points from the edge of the main road was determined taking into account topography, plant cover and buildings. Measurement profiles were determined in places which enabled direct noise measurement from the main road burdened the least with local noise sources. The measurement point closest to the road was at a distance of $100 \mathrm{~m}$, and the furthest one was at $300 \mathrm{~m}$. The selection of measurement points was guided by the principle that they would best describe the acoustic climate created by traffic on a selected road section [20].

\section{Results}

Contamination of air emitted in the road transport sector depends on many factors including, among other things, fuel composition, engine characteristics and maintenance, vehicle type, vehicle speed or traffic jams. Figure 2 shows concentrations of sulfur and nitrogen dioxides in atmospheric air at specified measurement points.

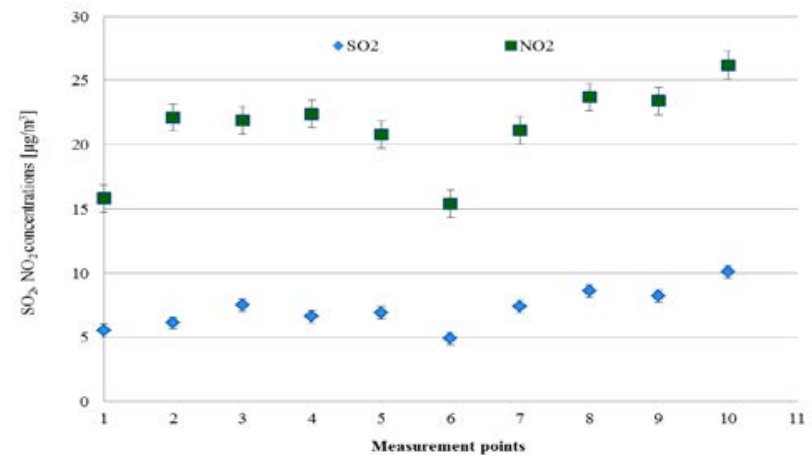

Fig. 2 Concentration of sulfur and nitrogen dioxides in the air at measurement points $\left[\mu \mathrm{g} / \mathrm{m}^{3}\right]$

The instantaneous sulfur dioxide concentrations along the analyzed section of the eastern ring road of Lodz ranged from 5 to $10 \mu \mathrm{g} / \mathrm{m}^{3}$. The highest content of $\mathrm{SO}_{2}$ in the air was recorded in the center of the Lodz agglomeration in the built-up area and in the region where the A1 motorway connects to the A2 motorway, where we observe increased traffic in comparison with the analyzed part of the eastern ring road of Lodz. The instantaneous concentrations of nitrogen dioxide outside the built-up area ranged from 15 to $24 \mu \mathrm{g} / \mathrm{m}^{3}$, while in the city center they were slightly higher, reaching $26 \mu \mathrm{g} / \mathrm{m}^{3}$. The lowest concentrations of $\mathrm{SO}_{2}$ and $\mathrm{NO}_{2}$ were recorded at measurement points located behind energy absorbing barriers at point 1 in Skoszewy West and at point 6 in Wisniowa Gora East.

The impact of road transport on soil contamination has been a subject of numerous studies conducted in different regions of the world. Heavy metal compounds released from vehicle operating processes and contained in particulate matter react with soil components or are adsorbed on humus colloids. Accumulation of heavy metals is observed mainly on the soil surface. Heavy metals can remain in the soil for a long time and affect the content of these compounds in plants. Figure 3 shows the content of selected heavy metals in soil samples collected in the vicinity of the analyzed Lodz ring road. 


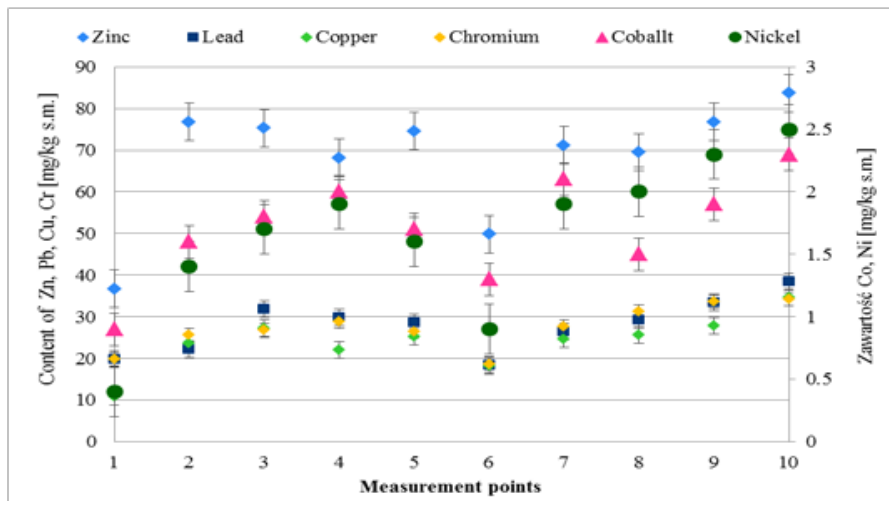

Fig. 3 Content of zinc, lead, copper, chromium, cobalt and nickel in the soil [mg/kg d.m.]

Soil samples taken along the eastern ring road of Lodz are characterized by different contents of heavy metals along the studied road section. Analysis of the samples shows that soil collected at the measuring points located in the immediate vicinity of the road is characterized by the highest zinc content equal to $35-85 \mathrm{mg} / \mathrm{kg} \mathrm{d} . \mathrm{m}$. Zinc is commonly used in brake and clutch discs as well as in lubricating oils and tires. As a result, in places where cars need to brake more often and so wear off their tires and elements of the braking system, we can observe higher concentrations of this metal. Lead contaminants in the soil amounted to $20-40 \mathrm{mg} / \mathrm{kg}$ d.m. The concentration of cobalt and nickel is low and results from the natural content of these metals in the environment.

The content of heavy metals in the soil collected along the eastern ring road of Lodz is lower than in the area of the intersection of the A1 and A2 motorways and in the city center. The studied road section is the shortest one, and it can be concluded that for a short period of time the process of soil contamination is very slow.

Following changes in the noise level along the analyzed section of the eastern ring road of Lodz different noise intensities were observed. The analyzed section lies in the areas with different land cover (forests, fields, meadows, scattered farm buildings) and diverse housing density as well as the density of local roads. As can be seen from the studies conducted, in all noise profiles the permissible noise levels were exceeded (Figures 4-6). In assessing the level of road noise, the results obtained were compared with the permissible noise level specified in the Ordinance of the Ministry of the Environment on permissible noise levels in the environment [21]. These standards are dependent on the type of emission source, land use and time of day. The highest noise levels were recorded in the immediate vicinity of the road edge.

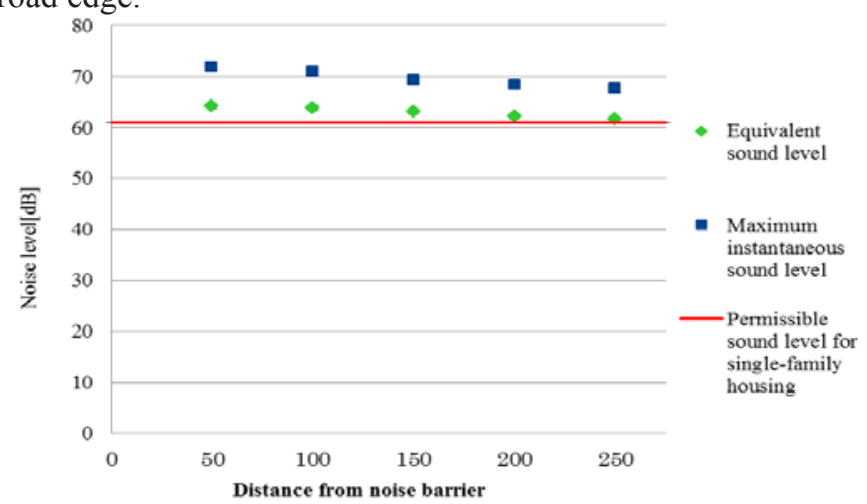

Fig. 4 Noise level at Rezerwat Wiączyń Street 


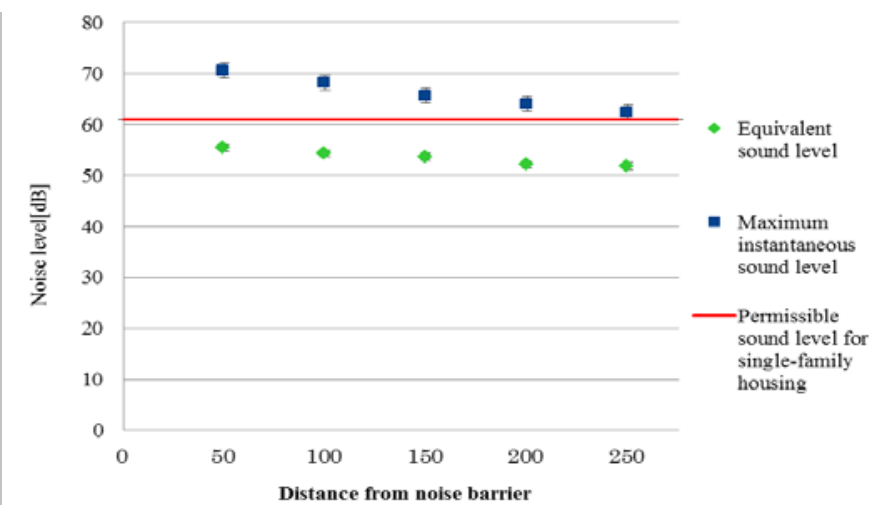

Fig. 5 Noise level at Nery Street

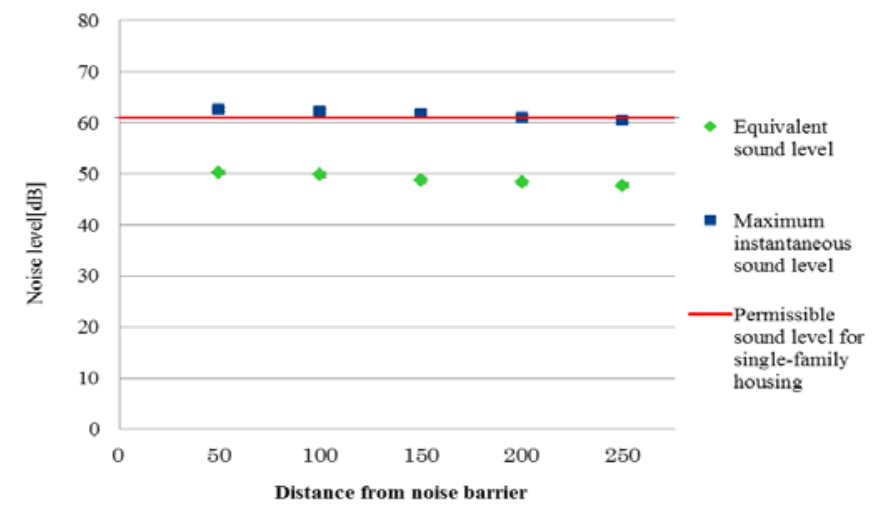

Fig. 6 Noise level at Taborowa Street

In the case of Wiaczyn Reserve Str. it was $71 \mathrm{~dB}(\mathrm{~A})$ and a similar value was recorded on Nery road $-70 \mathrm{~dB}(\mathrm{~A})$. The smallest exceeding of the allowed standards was noted at Taborowa Street. With the smooth movement of vehicles on motorways, the level of noise was lesser than the noise generated by frequent braking and acceleration (especially of heavy vehicles).

Studies show that the noise emitted by cars moving on the motorway decreases evenly as they move away from its edge. It has been found that a significant reduction in noise occurs at a distance of $250 \mathrm{~m}$ from the road. Moving away from the motorway, local factors gain importance in shaping the acoustic climate of the place, while traffic noise from the road is heard as steady humming noise.

\section{Conclusions}

The development of road transport is an important factor in the economic progress of the country and at the same time a significant source of environmental pollution and nuisance for man. The construction of expressways is a human intervention in ecological systems of the natural environment. It causes permanent occupation of the area under the planned route, temporary occupation of access roads to construction sites, warehouses for materials and machinery, aggregate extraction sites and others. From these areas the vegetation and soil layers are removed, the terrain is transformed and water relations changed. The development of expressway network has a significant impact on changes in the distribution of animal species, their habitats and causes environmental pollution. 
Massive use of vehicles results in multilateral, negative environmental impacts associated with loading the atmosphere and land-water environment with contaminants, noise increase and barriers on animal migration routes [22-26].

The expansion of the high-speed road network in Poland caused that road transport, as the most commonly used form of transport, has contributed significant to the environmental pollution. Car exhausts containing sulfur and nitrogen dioxides are much more harmful to people than industrial pollutants. Vehicle pollution spreads at low altitudes in the immediate vicinity of human habitats. These pollutants also cause damage to buildings, agricultural crops and forests.

On the analyzed part of the eastern ring road of Lodz, the concentrations of sulfur and nitrogen dioxides are significantly lower than the permissible levels of the analyzed substances in the air in accordance with the Ordinance of the Ministry of Environment on levels of certain substances in the air [27]. The value of a one-hour permissible level of nitrogen dioxide is $200 \mu \mathrm{g} / \mathrm{m}^{3}$, and sulfur dioxide $350 \mu \mathrm{g} / \mathrm{m}^{3}$. The emission of pollutants into the air coming from the car traffic is small and does not exceed the permissible values and at the same time does not significantly affect the environment.

Based on the analysis of soil samples, it can be concluded that not only traffic density but also duration of its impact on the soil is a very important element of the current sanitary condition. The analyzed part of the eastern ring road of Lodz is a relatively new investment, so the resulting heavy metal concentrations in the soil samples collected along this section are significantly lower than the admissible values described in the Ordinance of the Ministry of the Environment on the way of assessing the pollution of the earth's surface [28]. For example, the permissible content of zinc in the soil taken at a depth of 0 to $0.25 \mathrm{~m}$ is $300 \mathrm{mg} / \mathrm{kg} \mathrm{s.m}$., and it is almost three times higher than the determined concentration in the soil collected along the Lodz eastern ring road. Slightly higher concentrations, but also below the norm values were observed in soil samples taken in the city center. It should be noted, however, that such a trend may also be a consequence of the reduction of emissions due to technological changes (newer engine generations). At present, it cannot be confirmed that the state of soil pollution has decreased due to putting this motorway section into operation.

The conducted noise analyzes allowed us to determine the noise level along the eastern ring road of Lodz Its intensity depends on many factors such as topography, land use and weather conditions, local noise sources. In the immediate vicinity of the road, despite the use of energy absorbing barriers, there is no possibility of eliminating noise. In order to provide people with adequate living conditions, roads should be more than 200 to 300 meters away from residential buildings. Protection against roadway noise requires a wide range of activities from the planning stage to the proper traffic organization. It should be borne in mind that noise barriers are not the only way to reduce noise levels in road surroundings. It is necessary to use alternative methods of limiting undesirable noise emissions, including natural barriers in the form of broad green strips along the roads.

The conducted research allowed us to determine preliminarily the impact of the eastern ring road of Lodz on individual components of the environment. The results obtained constitute the first stage of the initiated monitoring of the environment on the analyzed road section and a full diagnosis of its environmental impact will be possible over the next few years.

\section{Conclusions}

1. D. Turek, Road Transport in Poland in the years 2014, 2015 (Central Statistical Office, Warsaw, 2017 ) 
2. M. van Poppel, L.I. Panis, E. Govarts, J. van Houtte, W. Maenhaut, Atmos. Environ., 60 (2012)

3. J.L. Durant, C.A. Ash, E.C. Wood, S.C. Herndon, J.T. Jayne, W.B. Knighton, M.R. Canagaratna, J.B. Trull, D. Brugge, W. Zamore, C.E. Kolb, Atmos. Chem. Phys., 10 (2010)

4. N.L. Gilbert, S. Woodhouse, D.M. Stieb, J.R. Brook, Sci. Tot. Environ., 312 (2003)

5. S. Hu, S. Friun, K. Kozawa, S. Mara, S.E. Paulson, A.M. Winer, Atmos. Environ., 43 (2009)

6. C. Hueglin, B. Nuchmann, R.O. Weber, Atmos. Environ., 40 (2006)

7. N.A.H. Janssen, P.H.N. van Vliet, F. Aarts, H. Harssema, B. Brunekreef, Atmos. Environ., 35 (2001)

8. M.P. Keuken, S. Jonkers, I.R. Wilmink, J. Wesseling, Sci. Tot. Environ., 408 (2010)

9. M. Kohler, U. Corsmeier, U. Vogt, B. Vogel, Atmos. Environ., 39 (2005)

10. M.C. Roorda-Knape, N.A.H. Janssen, J. de Hartog, P.H.N. van Vliet, H. Harssema, B. Brunkekreef, Sci. Tot. Environ, 235 (1999)

11. Y. Zhu, W.C. Hinds, S. Kim, S. Shen, C. Sioutas, Atmos. Environ., 36 (2002)

12. M.B.A. Dijkema, S.C. van der Zee, B. Brunekreef, R.T. van Strien, Atmos. Environ., 42 (2008)

13. N. Barros, T. Fontes, M.P. Silva, M.C. Manso, Transport. Res. A-Pol., 50 (2013)

14. P. Leisen, Sci. Tot. Environ., 134 (1993)

15. H. Pleijel, A. Ahlfors, L. Skärby, G, Pifl, G. Selldén, Å. Sjödin, Sci. Tot. Environ., 146-147 (1994)

16. L. Jiang, J. Kang, Sci. Tot. Environ., 543 (2016)

17. A. Pashkevich, M. Beliakova, A. Ivanov, A. Purju, Procedia Engineering, 178 (2017)

18. E.J. Judge, K. Werpachowski, M. Wishardt, J. Transp. Geogr., 12 (2004)

19. M. Karlson, U. Mörtberg, B. Balfors, Environ. Impact. Asses., 48 (2014)

20. Ordinance of the Ministry of Environment of 16 June 2011 on the requirements for measurements of substances or energy levels in the environment to be carried out by the manager of road, tram line, airport or port (Journal of Laws 2011 No. 140, item 824)

21. Ordinance of the Ministry of the Environment of 1 October 2012 on permissible noise levels in the environment (Journal of Laws 2012, item 1109)

22. A.H. Versluis, Sci. Tot. Environ., 146-147 (1994)

23. C. Beckx, W. Lefebvre, B. Degraeuwe, M. Vabhulsel, B. Kochan, T. Bellemans, S. Dhondt, L.I. Panis, Transport. Res. D-Tr E., 18 (2013)

24. T. Aljazzar, B. Kocher, Transport. Res. P., 14 (2016)

25. F. van der Hoeven, Tunn. Undergr. Sp. Tech., 26 (2011)

26. L.W. Gill, P. Ring, B. Casey, N.M.P. Higgins, P.M. Johnston, Sci. Tot. Environ., 601602 (2017)

27. Ordinance of the Ministry of the Environment of 24 August 2012 on the levels of certain substances in the air (Journal of Laws 2012, item 1031)

28. Ordinance of the Ministry of the Environment of 1 September 2016 on the way of assessing the pollution of the earth's surface (Journal of Laws 2016, item 1395) 